\title{
Pan-European multi-crop model ensemble simulations of wheat and grain maize under climate change scenarios
}

Heidi Webber ${ }^{1 *}$, Diane Cooke ${ }^{1}$, Frank Ewert ${ }^{1,2}$, Jørgen E. Olesen ${ }^{3}$, Stefan Fronzek ${ }^{4}$, Alex C. Ruane ${ }^{5}$, Pierre Martre ${ }^{6}$, Brian Collins ${ }^{7}$, Marco Bindi ${ }^{8}$, Roberto Ferrise ${ }^{8}$, Nándor Fodor ${ }^{10}$, Clara Gabaldón-Leal ${ }^{11}$, Thomas Gaiser ${ }^{2}$, Mohamed Jabloun ${ }^{12}$, Kurt-Christian Kersebaum ${ }^{1,17}$, Jon I. Lizaso ${ }^{13}$, Ignacio J. Lorite ${ }^{11}$, Loic Manceau ${ }^{6}$, Marco Moriondo ${ }^{9}$, Claas Nende ${ }^{1,16}$, Alfredo Rodríguez ${ }^{13,14}$, Margarita Ruiz-Ramos ${ }^{13}$, Mikhail A. Semenov ${ }^{15}$, Tommaso Stella ${ }^{1}$, Pierre Stratonovitch ${ }^{15}$ and Giacomo Trombi ${ }^{8}$

${ }^{1}$ Leibniz Centre for Agricultural Landscape Research (ZALF), Eberswalder Straße 84, 15374 Müncheberg, Germany

2 Institute of Crop Science and Resource Conservation (INRES), University of Bonn, Bonn, Germany

${ }^{3}$ Department of Agroecology, Aarhus University, Tjele, Denmark

${ }^{4}$ Finnish Environment Institute, Helsinki, Finland

${ }^{5}$ NASA Goddard Institute for Space Studies, New York, NY 10025, USA

${ }^{6}$ LEPSE, Univ. Montpellier, INRAE, Montpellier SupAgro. Montpellier, France

${ }^{7}$ Centre for Crop Science, Queensland Alliance for Agriculture and Food Innovation (QAAFI),

University of Queensland, Toowoomba, Australia

8 University of Florence, Florence, Italy

${ }^{9}$ Institute of BioEconomy, National Research Council, Florence, Italy

${ }^{10}$ Centre for Agricultural Research, Martonvásár, Hungary

${ }^{11}$ Institute of Agricultural and Fisheries Research and Training (IFAPA), Cordoba, Andalusia, Spain

12 Plant Production Systems Group, Wageningen University \& Research, Wageningen, The Netherlands

${ }^{13}$ CEIGRAM, Universidad Politécnica de Madrid, Madrid, Spain

14 DAEF, Universidad de Castilla-La Mancha, Toledo, Spain

${ }^{15}$ Rothamsted Research, Harpenden, United Kingdom

${ }^{16}$ University of Potsdam, Germany

17 Global Change Research Institute, The Czech Academy of Scienes, Brno, Czech Republic.

*e-mail: webber@zalf.de

Abstract: The simulated data set described in this paper was created with an ensemble of nine different crop models: HERMES (HE), Simplace<Lintul5,Slim3, FAO-56 ET0> (L5), SiriusQuality (SQ), MONICA (MO), Sirius2014 (S2), FASSET (FA), 4M (4M), SSM (SS), DSSAT-CSM IXIM (IX). Simulations were performed for grain maize (six models) and winter wheat (eight models) under diverse conditions over agricultural land areas of the EU-27 at a $25 \times 25 \mathrm{~km}$ spatial resolution. Simulations were drawn from combinations of three representative concentration pathways and climate outputs from five general circulation models for time periods 2040-2069 and 2070-2099. Historical climate data was the basis for simulation years 1980-2010 and considered as a baseline. Simulation results can be used to analyze crop responses to changing climatic variables. This data paper describes the creation, motivation and format of the simulation results to enable reuse of the data set. It also offers some possible further uses of the dataset in other contexts.

Keywords: crop modelling, climate change impacts, European Union, maize, wheat, heat stress, drought.

1 BACKGROUND: The data set consists of simulations from historical (1980-2010) and scenario periods (2040-2069 and 2070-2099) for six grain maize (MZ) and eight winter wheat (WW) processbased models. The models were applied on a spatial grid of $25 \mathrm{~km}$ resolution across the EU-27 (Austria, Belgium, Bulgaria, Cyprus, Denmark, Finland, France, Germany, Greece, Ireland, Italy, Luxembourg, Malta, Netherlands, Portugal, Romania, Spain, Sweden, United Kingdom, Czech Republic, Estonia, Hungary, Latvia, Lithuania, Poland, Slovenia, Slovak Republic). The original purpose of this data set was to analyze the drivers of historical yield variability at both the national and subnational (NUTS2) levels, as well as the drivers of yield change under climate change for wheat and maize across Europe (Webber et al. 2018a). These two important food security crops are interesting to compare, as they have contrasting photosynthesis pathways (C3 and $\mathrm{C} 4$ ), a major determining factor of crop response to a change in ambient $\mathrm{CO}_{2}$ levels. The two crops also differ in their main growing season (autumn versus spring sown for winter wheat and maize, respectively). A detailed description of the simulations, results 
and discussion from this analysis are reported in Webber et al. (2018a). The data set described in this paper can be accessed from doi: 10.4228/ZALF.DK.88.

2 DATA CREATION PROCESS: A multi-model ensemble was used in this study to capture uncertainty associated with modeled processes and associated parameterizations. The nine crop models in the ensemble were: HERMES (HE), Simplace<Lintul5,Slim3, FAO-56 ETO> (L5), SiriusQuality (SQ), MONICA (MO), Sirius2014 (S2), FASSET (FA), 4M (4M), SSM (SS), DSSAT-CSM IXIM (IX). Models were selected based on their ability to simulate heat and drought stresses, as well as the interest of the respective modelling groups to participate in the study. Six of the models were also able to simulate crop canopy temperature (FA, L5, HE, SS, SQ and S2; see Table 1) allowing for the interaction of high temperature, drought stress and $\mathrm{CO}_{2}$. More detailed model descriptions are provided in key references (Table 1) and in the SI materials of Webber et al. (2018a, b). A common protocol was defined and used by all modelers to standardize the modeling procedure, climate and soil data inputs as well as crop management practices. The complete protocol is provided in the supplemental methods of Webber et al. (2018a). All models were applied to the same spatial extent of EU-27 (Fig. 1), for 8,084 grids cells of $25 \times 25 \mathrm{~km}$ resolution where soil data indicated at least a $40 \mathrm{~cm}$ rooting depth (see Figure 1). Data for sowing, anthesis and harvest dates were sourced from Eurostat ${ }^{1}$, aggregated to 13 environmental zones and resampled to the simulation grid cells. Soil data were sourced from the JRC European Soil Data Portal. $^{2}$

Table 1: Overview of models and key settings, including crop(s) simulated (winter wheat, grain maize, or both), processes affected by elevated $\mathrm{CO}_{2}$ (canopy temperature, transpiration and/or radiation use efficiency, RUE) and the approach to simulate canopy temperature (CT). The three CT approaches include: empirical (EMP), energy balance assuming neutral stability (EBN) or energy balance correcting for atmospheric stability conditions (EBSC). 'NA' indicates that CT was not simulated.

\begin{tabular}{l|l|l|l|l}
\hline Model name (abrv) & Crop & $\begin{array}{l}\text { Processes affected by } \\
\mathbf{C O}_{2}\end{array}$ & CT & Key references \\
\hline HERMES (HE) & both & $\begin{array}{l}\text { canopy temperature, } \\
\text { transpiration and RUE }\end{array}$ & EBN & Kersebaum 2017 \\
\hline $\begin{array}{l}\text { Simplace<Lintul5,Slim } \\
\text { 3, FAO-56 ET0> (L5) }\end{array}$ & both & $\begin{array}{l}\text { canopy temperature, } \\
\text { transpiration and RUE }\end{array}$ & EBSC & $\begin{array}{l}\text { Webber et al. } \\
2016\end{array}$ \\
\hline SiriusQuality (SQ) & $\begin{array}{l}\text { winter } \\
\text { wheat }\end{array}$ & RUE & EBN & $\begin{array}{l}\text { Martre and } \\
\text { Dambreville 2018 }\end{array}$ \\
\hline MONICA (MO) & both & transpiration and RUE & NA & $\begin{array}{l}\text { Nendel et al. } \\
2011\end{array}$ \\
\hline Sirius2014 (S2) & $\begin{array}{l}\text { winter } \\
\text { wheat }\end{array}$ & RUE & EBN & $\begin{array}{l}\text { Jamieson et al. } \\
1998\end{array}$ \\
\hline FASSET (FA) & both & $\begin{array}{l}\text { canopy temperature, } \\
\text { transpiration, RUE }\end{array}$ & EMP & $\begin{array}{l}\text { Olesen et al. } \\
2002\end{array}$ \\
\hline 4M (4M) & both & transpiration and RUE & NA & Fodor et al. 2014 \\
\hline SSM (SS) & $\begin{array}{l}\text { winter } \\
\text { wheat }\end{array}$ & $\begin{array}{l}\text { canopy temperature, } \\
\text { transpiration, RUE }\end{array}$ & EBN & Soltani et al. 2013 \\
\hline $\begin{array}{l}\text { DSSAT-CSM IXIM } \\
\text { (IX) }\end{array}$ & $\begin{array}{l}\text { grain } \\
\text { maize }\end{array}$ & transpiration and RUE & NA & Lizaso et al. 2017 \\
\hline
\end{tabular}

${ }^{1}$ https://ec.europa.eu/irc/en/mars

2 https://esdac.jrc.ec.europa.eu/resource-type/european-soil-database-soil-properties 

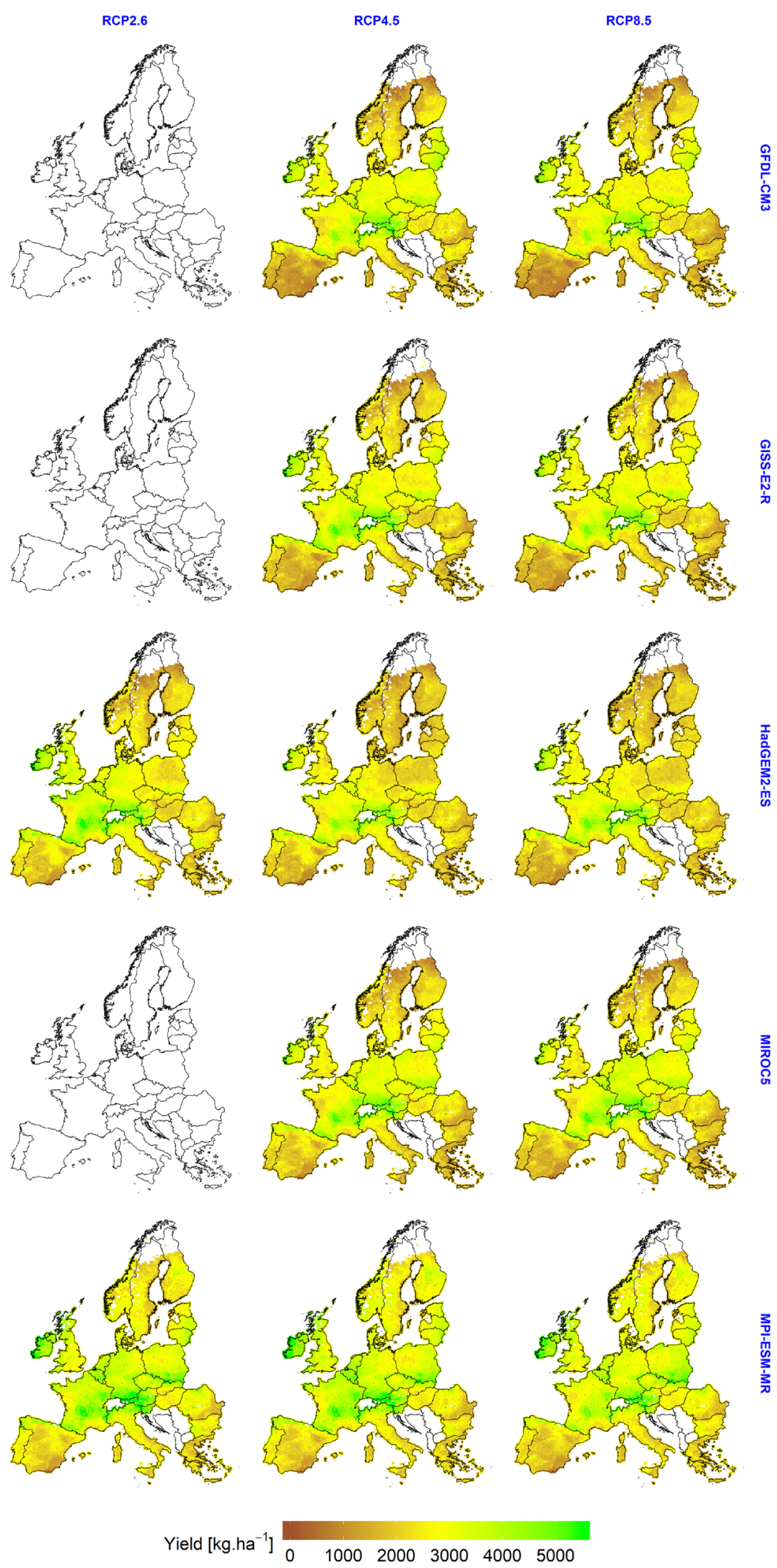

Figure 1. Maps of average yield (kg/ha) for winter wheat for time period 2 (2040-2069), assuming elevated $\mathrm{CO}_{2}$ levels $(429,499$ and $571 \mathrm{ppm}$, for RCP2.6, 4.5 and 8.5, respectively) for each GCM (rows) and RCP (columns). These maps are based on simulations carried out by the FA model under rainfed conditions, including heat and drought stress, corresponding to Treatment 6 (T6) (see Figure 3). 
2.1 Climate inputs: Observed meteorological data for the baseline period (period "0" $=1980-2010$ ) were extracted from the Crop Growth Monitoring System (CGMS) of the Joint Research Centre (JRC) archive $^{3}$. The JRC site-specific daily weather data is based on more than 3000 sites across Europe. The data is representative of agricultural land use and is interpolated to a regular grid at a spatial resolution of $25 \mathrm{~km}$. Climate scenario data were constructed using an enhanced delta method (Ruane et al. 2015) for two periods (periods:"2"= 2040-2069 and "3"= 2070-2099). For each period, three representative concentration pathways (RCP; 2.6, 4.5, or 8.5) were coupled with five GCMs (GFDL-CM3, GISS-E2-R, HadGEM2-ES, MIROC5, and MPI-ESM-ER). Only two GCMs were available for RCP 2.6 (HadGEM2ES and MPI-ESM-MR), whereas all five GCMs were available for RCP 4.5 and RCP 8.5 (Fig. 1 and Fig. 2). For each climate scenario, GCM and time period combination, simulations were conducted twice: the first set with atmospheric $\mathrm{CO}_{2}$ concentration set at ambient levels corresponding to the historical baseline period (360 ppm) and a second set with elevated $\mathrm{CO}_{2}$ (Fig. 2). Elevated $\mathrm{CO}_{2}$ concentrations were determined based on the associated RCP and time period (429 and $442 \mathrm{ppm}$ for RCP2.6 time periods 2 and 3, 499 and 532 ppm for RCP4.5 time periods 2 and 3, 571 and 801 ppm for RCP 8.5 and time periods 2 and 3 , respectively). For each scenario and time period, concentrations were based on values listed in the 2013 IPCC report (IPCC 2013). From these values, a central-year concentration, based on projections for the middle of the range of years, was assigned to each time period (see McDermid et al. 2015). As RCP 2.6 and 4.5 consider $\mathrm{CO}_{2}$ mitigation measures, the increase in $\mathrm{CO}_{2}$ concentration from time period 2 to 3 for these two scenarios is less than that for RCP 8.5. In total, there were 49 combinations used in the study (see Figure 2). The original climate data used in the study is available from doi 10.4228/ZALF.DK.59. An updated climate dataset that corrects for temperatures at high elevations is available at doi 10.4228/ZALF.DK.94. A detailed description of the creation of the climate data can be found in Fronzek et al., 2018b.

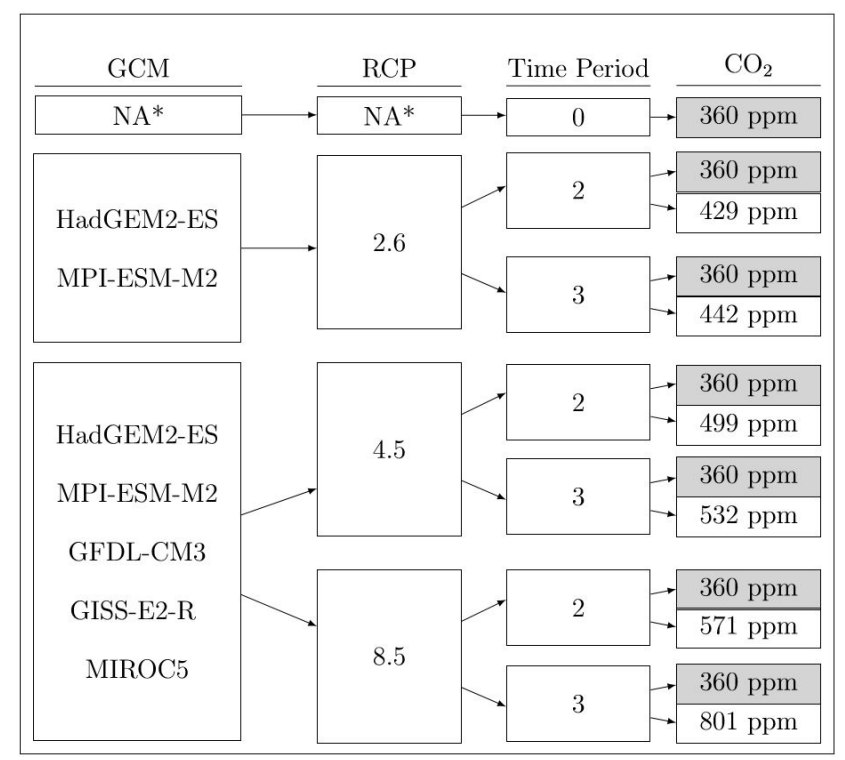

Figure 2. Simulations were conducted for 49 sets of climate and $\mathrm{CO}_{2}$ concentration data. Climate data consist of 48 sets corresponding to climate scenarios defined by combinations of global climate models (GCM), representative concentration pathways (RCP), time period $(2=2040-2069,3=2070-2099)$, and $\mathrm{CO}_{2}$ level. One simulation set was conducted for a baseline climate (period $=0,1980-2010$; $\mathrm{CO}_{2}=360 \mathrm{ppm},{ }^{*} \mathrm{GCM}=\mathrm{NA}$ and $\mathrm{RCP}=\mathrm{NA}$ correspond to the fact that no GCM or RCP is applicable for observational historical data used in this study)

2.2 Soil inputs: The original soil data was sourced from the JRC European Soil Data Portal ${ }^{4}$ at $1 \mathrm{~km}$ resolution and included textural classes, depth available to roots, total available water content (TAWC), bulk density (BD), and soil organic carbon (SOC). To select for grids under current agricultural land use within the EU-27, soil layers were resampled to match the $250 \times 250$ m resolution Corine 2006 Land Cover Map Version 175. Since data for Greece was not available from this map, the Corine 2000 Land Cover v16 map was used for Greece. Further, only soils with a depth of $40 \mathrm{~cm}$ or greater were included.

\footnotetext{
3 https://ec.europa.eu/irc/en/mars

${ }^{4}$ https://esdac.jrc.ec.europa.eu/resource-type/european-soil-database-soil-properties

5 http://www.eea.europa.eu/data-and-maps/data/ds resolveuid/a47ee0d3248146908f72a8fde9939d9d
} 
These data were used to derive estimates of soil water at saturation, field capacity and permanent wilting point, needed as inputs for the crop models.

2.3 Phenology and crop management inputs: Phenology observations of sowing, emergence, anthesis and harvest or maturity dates from the JRC AgriCast4 database ${ }^{6}$ were used by the modelling groups to calibrate phenology parameters with the historical weather data. Modelling groups calibrated their respective phenology parameters (eg, thermal times) to match observed anthesis and maturity dates. The resulting parameters for each model were kept constant for subsequent scenario simulations, with the explicit assumption that there was no adaption in crop variety.

2.4 Treatments: For each of the 49 climate combinations, two crops (grain maize, MZ, and winter wheat, WW) and up to six treatments (Fig. 3) were simulated by the models, dependent on the respective model's ability to simulate both crops and each treatment. The treatments were numbered T1 to T6 and defined by combinations of irrigation status (full or rain), heat stress (on or off) and heat by drought interaction (on or off) (Fig. 3). The interaction of heat and drought stresses were estimated using simulated canopy temperatures. Models used different methods to simulate canopy temperature (Table 1), with detailed descriptions in Table 2 of the supplementary materials of Webber et al. 2018a. As treatments T3 and T6 used canopy temperature, they were only simulated by models that consider canopy temperature (FA, L5, HE, SS, SQ, and S2)

\begin{tabular}{|c|c|c|c|}
\hline \multicolumn{4}{|c|}{ Treatments } \\
\hline ID & $\mathrm{T}$ & $\begin{array}{l}\text { Irrigation } \\
\text { status }\end{array}$ & $\begin{array}{l}\text { Production case } \\
\text { (code) }\end{array}$ \\
\hline $\mathrm{T} 1$ & $\mathrm{~T}_{a i r}$ & Full & $\begin{array}{l}\text { Potential (Pot) with no } \\
\text { heat stress }\end{array}$ \\
\hline $\mathrm{T} 2$ & $\mathrm{~T}_{a i r}$ & Full & $\begin{array}{l}\text { Heat-limited with } \mathrm{T}_{a i r} \\
\text { (HL_air) }\end{array}$ \\
\hline T3 & $\mathrm{T}_{\text {canopy }}$ & Full & $\begin{array}{l}\text { Heat-limited with } \mathrm{T}_{c} \\
\text { (HL_can) }\end{array}$ \\
\hline $\mathrm{T} 4$ & $\mathrm{~T}_{a i r}$ & Rain & $\begin{array}{l}\text { Water-limited with no } \\
\text { heat stress (WL) }\end{array}$ \\
\hline T5 & $\mathrm{T}_{\text {air }}$ & Rain & $\begin{array}{l}\text { Water-heat-limited with } \\
\mathrm{T}_{\text {air }} \text { (WHL_air) }\end{array}$ \\
\hline $\mathrm{T} 6$ & $\mathrm{~T}_{\text {canopy }}$ & Rain & $\begin{array}{l}\text { Water-heat-limited with } \\
\mathrm{T}_{c} \text { (WHL_can) }\end{array}$ \\
\hline
\end{tabular}

Figure 3. Six treatments were simulated, defined by irrigation status (full irrigation (Full) or rainfed (Rain)), stress type considered (heat or drought) and whether stress interactions were considered by using air ( $T_{\text {air }}$ ) or canopy temperatures ( $\left.T_{\text {canopy }}, T_{c}\right)$. Treatments using canopy temperature (T3 and $T 6$ ) were only simulated by 6 of the models (FA, L5, HE, SS, SQ, and S2).

3 FILE FORMAT AND ANNOTATION: All files in the data set are comma separated value (csv) files compressed into a gzip format. Each file comprises the outputs for all crops (MZ, WW), treatments (TrtNo), scenarios by GCMs combination (sce), $\mathrm{CO}_{2}$ concentrations (CO2), periods (period) and year carried out by a single model (Model) and for a single simulation grid and is named as "EU_HS_2digitModelCode_row_col.csv.gz". As an example, the file with model outputs from model 4M with input data associated with grid cell in row 32 and column 125 would be named EU_HS_4M_32_125.csv.gz (Table 2). Additionally a redundant identifier is defined for the combination of scenario, GCM, and $\mathrm{CO}_{2}$ concentration (ClimPerCO2_ID), which are further defined in the Supplemental Materials of Webber et al. 2018a. Definitions and units for the variables found in the headers of each file are listed in doi 10.4228/ZALF.DK.88 and given (from top to bottom) in the same order as they appear in the files (from left to right). Header and variables are the same in every file of the data set. Missing values in the files are denoted as "NA" (Table 2). Data was annotated using metadata standards defined by DataCite 4.1 (DataCite 2017).

${ }^{6}$ https://ec.europa.eu/irc/en/mars 


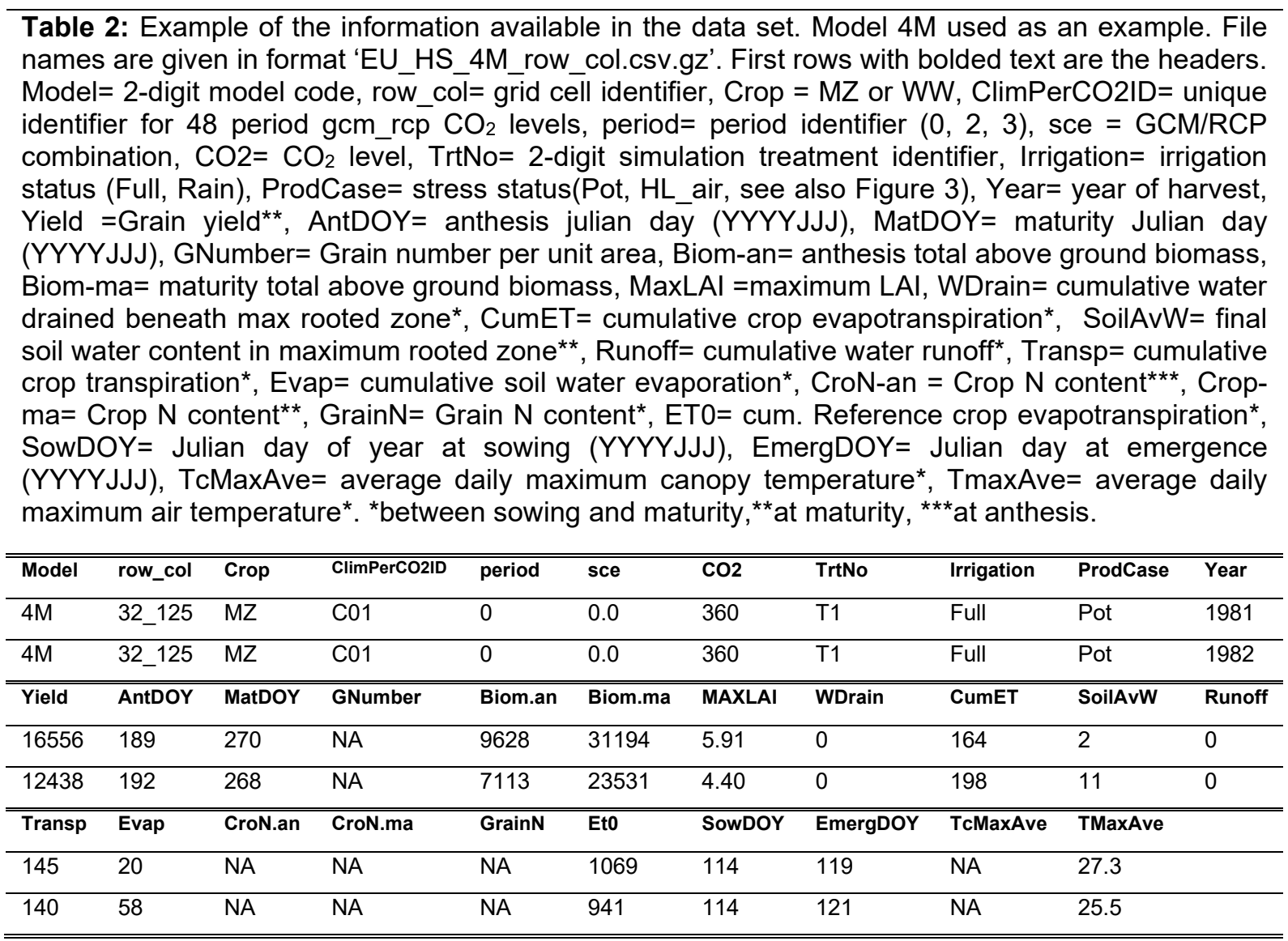

4 OPPORTUNITIES FOR REUSE: The data set may serve as the basis for further analysis of maize and wheat average yields and inter-annual variability, as well as crop response to climate and elevated $\mathrm{CO}_{2}$ across Europe. Beyond quantifying and identifying impacts on yield, the dataset could also be used to assess changing water use and water demand under both rainfed and irrigated conditions. As such, it could inform risk assessments and irrigation design studies. Further, the dataset could potentially be linked with remote sensing data to understand patterns observed in soil-water, surface temperature or leaf area related indices, and how they may be affected by climate change. It also has the potential to act as a benchmark for more detailed and localized adaptation studies by providing European scale trends against which regional changes can be compared.

\section{ACKNOWLEDGMENTS}

H.W., T.G and F.E. acknowledge support from the FACCE JPI MACSUR project through the German Federal Ministry of Food and Agriculture (2815ERA01J). Support from the SUSTAg project funded through the German Federal Ministry of Food and Agriculture is acknowledged by H.W. and F.E. (031B0170B). J.E.O. and M.J. were funded by Innovation Fund Denmark (5105-00001B). S.F. received financial support from the Academy of Finland (decision 277276) and the Finnish Ministry of Agriculture and Forestry (MMM) through FACCE-MACSUR. A.R. was supported by the National Aeronautics and Space Agency Science Mission Directorate (WBS 281945.02.03.06.79). M.Bi., R.F., M.M., and G.T. acknowledge financial support from the JPI FACCE MACSUR2 project, funded by the Italian Ministry for Agricultural, Food, and Forestry Policies (D.M. 24064/7303/15 of 26/Nov/2015). N.F.'s contribution was supported by the Széchenyi 2020 program, the European Regional Development Fund-“Investing in your future" and the Hungarian Government (GINOP-2.3.2-15-2016-00028). M.R.R. and A.Ro. acknowledge support from MINECO (APCIN2016-0005-00-00). A.Ro. acknowledges support from Comunidad de Madrid (Spain) and Structural Funds 2014-2020 (ERDF and ESF), project AGRISOSTCM S2018/BAA-4330. M.A.S. and P.S. received grant-aided support from the BBSRC Designing Future Wheat programme [BB/P016855/1]. We thank R.P. Rötter for climate scenario construction. The contributions of Andreas Enders and Gunther Kraus in facilitating the data transfer and processing are acknowledged and appreciated.

\section{REFERENCES}

DataCite Metadata Working Group. 2017. DataCite Metadata Schema Documentation for the Publication and Citation of Research Data. Version 4.1. DataCite e.V. doi: 10.5438/0014. 
Fronzek, S., Webber, H., Rötter, R., Ruane, A. and Ewerts, F., 2018a. A daily time-step observed and scenario climate dataset on a European grid for crop modelling applications (version 1). doi: 10.4228/ZALF.DK.59.

Fronzek, S., Webber, H., Rötter, R., Ruane, A. and Ewerts, F., 2018b. A daily time-step observed and scenario climate dataset on a European grid for crop modelling applications (version 2). doi: 10.4228/ZALF.DK.94.

IPCC, 2013. Annex II: Climate System Scenario Tables [Prather, M., Flato, G., Friedlingstein, P., Jones, C., Lamarque, J.-F., Liao, H., Rasch, P. (eds.)]. In: Stocker, T. et al. (Editors), Climate Change 2013: The Physical Science Basis. Contribution of Working Group I to the Fifth Assessment Report of the Intergovernmental Panel on Climate Change. doi: 10.1017/CBO9781107415324.030.

Jamieson, P. D., Semenov, M.A., Brooking I.R. and Francis, G. S. 1998. Sirius: a mechanistic model of wheat response to environmental variation. European. Journal. Agronomy. 8, 161-179. doi: 10.1016/S1161-0301(98)00020-3.

Lizaso, J., Ruiz-Ramos, M., Rodríguez, L., Gabaldon-Leal, C., Oliveir, J.A., Lorite, I.J., Rodríguez, A., Maddonni, G.A., Otegui, M.E., 2017. Modeling the response of maize phenology, kernel set, and yield components to heat stress and heat shock with CSM-IXIM. Field Crops Res. 214, 239-252. doi: 10.1016/j.fcr.2017.09.019.

Martre, P. and Dambreville, A., 2018. A model of leaf coordination to scale-up leaf expansion from the organ to the canopy. Plant Physiol. 176, 704-716. doi: 10.1104/pp.17.00986.

McDermid, S. P., et al. The AgMIP Coordinated Climate-Crop Modeling Project (C3MP): Methods and Protocols. Handbook of Climate Change and Agroecosystems: 191-220. doi: 10.1142/9781783265640 0008.

Nendel, C., Berg, M., Kersebaum, K.C., Mirschel, W., Specka, X., Wegehenkel, M., Wenkel, K.O., Wieland, R., 2011. The MONICA model: Testing predictability for crop growth, soil moisture and nitrogen dynamics. Ecological Modelling, Elsevier, vol. 222(9), pages 1614-1625. doi: 10.1016/i.ecolmodel.2011.02.018.

Olesen, J.E., Petersen, B.M., Berntsen, J., Hansen, S., Jamieson, P.D., Thomsen, A.G., 2002. Comparison of methods for simulating effects of nitrogen on green area index and dry matter growth in winter wheat. Field Crops Res. 74, 131-149 (2002). doi: 10.1016/S0378-4290(01)00204-0.

Ruane A.C., Winter, J.M., McDermid, S.P. and Hudson, N.I., 2015. AgMIP Climate Data and Scenarios for Integrated Assessment. In: Handbook of Climate Change and Agroecosystems. Imperial College Press, p 45-78. doi: 10.1142/9781783265640 0003 / doi: 10.1038/s41467-018-06525-2.

Soltani, A., Maddah, V., and Sinclair, T.R., 2013. SSM-wheat: a simulation model for wheat development, growth and yield. Int. J. Plant Prod. 7, 711-740. doi: 10.22069/ijpp.2013.1266.

Webber, H., Ewert, F., Kimball, B.A., Siebert, S., White, J.W., Wall, G.W., Ottman, M.J., Trawally, D.N.A., Gaiser, T., 2016. Simulating canopy temperature for modelling heat stress in cereals. Environ. Model. Softw. 77, 143-155. doi: 10.1016/i.envsoft.2015.12.003.

Webber, H., Ewert, F., Olesen, J.E., Müller, C., Fronzek, S., Ruane, A.C., Bourgault, M., Martre, P., Ababaei, B., Bindi, M., Ferrise, R., Finger, R., Fodor, N., Gabaldón-Leal, C., Gaiser, T., Jabloun, M., Kersebaum, K.-C., Lizaso, J. I., Lorite, I.J., Manceau, L., Moriondo, M., Nendel, C., Rodríguez, A., Ruiz-Ramos, M., Semenov, M.A., Siebert, S., Stella, T., Stratonovitch, P., Trombi, G. and Wallach, D., 2018a. "Diverging importance of drought stress for maize and winter wheat in Europe". Nature Communications 9(1): 1-11. doi: 10.1038/s41467-018-06525-2.

Webber, H., J. White, B. Kimball, Ewert, F., Asseng, S., Rezaei, E.E., and Martre, P., 2018b. "Physical robustness of canopy temperature models for crop heat stress simulation across environments and production conditions." Field Crops Research 216: 75 - 88. doi: 10.1016/j.fcr.2017.11.005.

Webber, H., Ababaei, B., Bindi, M., Ferrise, R., Fodor, N., Jabloun, M., Kersebaum, K.-C., Lizaso, J.I., Manceau, L., Moriondo, M., Martre, P., Nendel, C., Rodríguez, A., Ruiz-Ramos, M., Semenov, M.A., Siebert, S., Stella, T., Stratonovitch, P., Trombi, G., Ewert, F., Ruane, A.C., Lorite, I.J., Gabaldón-Leal, C., Gaiser, T. and Olesen, J., 2019. Diverging importance of drought stress for maize and winter wheat in Europe: Simulation Dataset. doi: 10.4228/ZALF.DK.88. 